\title{
Efek Waktu Milling Silika Abu Sekam Padi sebagai Filler Aspal Pen 60/70 terhadap Sifat Fisis dan Sifat Termal
}

\author{
Kartika Sari $^{1 *}$, Sunardi', Maghfirotul Umana ${ }^{1}$, Maretah Nawang Nonima1, dan Parmin Lumban Toruan² \\ ${ }^{1}$ Jurusan Fisika, FMIPA Universitas Jenderal Soedirman, \\ Jalan Dr. Soeparno 61 Karang Wangkal Purwokerto 53122 \\ ${ }^{2}$ Jurusan Fisika, FST Universitas PGRI Palembang, \\ Jalan Jend. A Yani Lrg Gotong royong 9/10 Ulu Palembang 30252 \\ *E-mail: kartika.sari@unsoed.ac.id
}

Diterima: 03-11-2021; Direvisi: 19-11-2021; Dipublikasi: 30-12-2021

\begin{abstract}
Abstrak
Aspal merupakan salah satu material memiliki sifat termoplastis yaitu mudah mencair jika dipanaskan sampai suhu tertentu dan membeku jika temperatur turun. Untuk meningkatkan sifat termoplastis aspal maka ditambahkanlah bahan lain seperti silika sebagai filler. Sintesis paduan silika abu sekam padi sebagai filler aspal pen60/70 dengan variasi waktu tanpa milling (S0) dan dengan milling sebesar 15 jam (S15) dilakukan dengan tujuan untuk menentukan porositas, daya serap air, kapasitas panas dan kalor jenis. Silika padi disintesis dengan metode sol gel. Serbuk silika abu sekam padi kemudian dimilling selama 15 jam. Komposisi paduan aspal pen60/70 dengan filler S0 dan S15 dibuat dengan perbandingan sebesar 1:2. Sampel dibuat dalam bentuk pellet. Kemudian, sampel dilakukan pengujian kapasitas panas dan kalor jenis dan daya serap air menggunakan alat uji Differential Scanning Calorimetry (DSC). Sedangkan, pengujian porositas menggunakan metode Archimides. Hasil uji porositas untuk sampel S0 dan S15 sebesar 6,0\% dan 10,7\%. Hasil pengujian daya serap air untuk S0 dan S15 sebesar 5,3\% dan 10,2\%. Sedangkan, hasil uji termal meliputi kalor jenis dan kapasitas panas menunjukkan nilai kalor jenis S0 dan S15 sebesar $7 \mathrm{~J} / \mathrm{kgK}$ dan $1 \mathrm{~J} / \mathrm{kgK}$ dan kapasitas panas $\mathrm{S} 0$ dan S15 sebesar 151,2 $\times 10-5 \mathrm{~J} / \mathrm{K}$ dan 23,4 × 10-5 J/K. Sehingga, dapat disimpulkan bahwa silika abu sekam padi hasil milling atau dengan variasi waktu milling dapat diaplikasikan sebagai filler aspal penetrasi 60/70 untuk meningkatkan sifat fisik dan sifat termal.
\end{abstract}

Kata kunci: aspal pen60/70; silika abu sekam padi; sifat fisis; sifat termal; waktu milling

\begin{abstract}
Asphalt is a material that has thermoplastic properties, which is easy to melt when heated to a certain temperature and freezes when the temperature drops. To improve the thermoplastic properties of asphalt, so other materials such as silica are added as a filler. Synthesis of rice husk ash silica alloy as asphalt filler pen60/70 with variations in time without milling (SO) and with the milling of 15 hours (S15) was carried out to determine porosity, water absorption, heat capacity, and specific heat. Rice silica was synthesized by the sol-gel method. Rice husk ash silica powder was then milled for 15 hours. The composition of the pen60/70 asphalt mixture with fillers SO and S15 was made in a ratio of 1:2. Samples are made in the form of pellets. Then, the samples were tested for heat capacity and specific heat and water absorption using the Differential Scanning Calorimetry (DSC). Meanwhile, the porosity test uses the Archimedes method. The results of the porosity test for samples SO and S15 were $6.0 \%$ and $10.7 \%$, respectively. The results of the water absorption test for SO and S15 were 5.3\% and 10.2\%, respectively. Meanwhile, the results of the thermal test including specific heat and heat capacity showed that the specific heat values of SO and S15 were $7 \mathrm{~J} / \mathrm{kg} \mathrm{K}$ and $1 \mathrm{~J} / \mathrm{kg} \mathrm{K}$ and the heat capacities of SO and S15 were $151.2 \times 10-5 \mathrm{~J} / \mathrm{K}$ and $23.4 \times 10-5 \mathrm{~J} / \mathrm{K}$. Thus, it can be concluded that the silica ash of rice husk as a result of milling or with variations in milling time can be applied as a 60/70 penetration asphalt filler to improve physical and thermal properties.
\end{abstract}

Keywords: asphalt pen60/70, rice husk ash silica, physical properties, thermal properties, milling time

\section{Pendahuluan}

Indonesia merupakan negara agraris dimana sebagian besar masyarakat berprofesi sebagai petani yang menanam padi. Produksi padi masyarakat Indonesia diproyeksikan meningkat sebesar 2,43\% per tahun selama periode 2005 - 2020. Berat padi sekitar 20 - 30\% merupakan sekam padi dan memiliki kandungan abu sekam padi sekitar 13 - 29\%. Abu sekam padi menunjukkan bahwa kandungan $\mathrm{SiO} 2$ mencapai $86,90 \%$ - 97,30\% silika abu sekam padi dapat dimanfaatkan sebagai 
modifikasi filler dalam aspal [1]. Filler berfungsi sebagai pengisi rongga udara pada material sehingga memperkaku lapisan aspal. Filler yang pernah digunakan seperti debu batu kapur, debu dolomite, atau semen Portland [2, 3, 4].

Salah satu alternatif filler yang sedang dikembangkan berasal dari alam yaitu silika sekam padi. Silika sekam padi diperoleh dengan metode sol-gel. Metode sol-gel merupakan proses yang digunakan dalam pembuatan material anorganik dengan menggunakan larutan pada suhu yang relatif rendah $[5,6,7]$. Penambahan silika abu sekam padi berfungsi untuk menyerap air pada aspal. Oleh karena itu, penambahan silika digunakan untuk memperbaiki karakteristik aspal dalam menahan efek suhu dan efek beban dalam perkerasan jalan. Jalan merupakan salah satu prasarana transportasi dalam kegiatan masyarakat, sehingga diperlukan jalan yang memiliki kualitas dan kuantitas yang memenuhi standar yang dipengaruhi oleh mutu bahan penyusunnya [8]. Aspal merupakan material perekat dengan unsur utama bitumen. Bitumen dapat tahan terhadap air dan bersifat perekat karena memiliki kombinasi penyusun yang sangat baik [9, 10].

Aspal memiliki sifat termoplastis yaitu mudah mencair jika dipanaskan sampai suhu tertentu dan membeku jika suhu turun. Peningkatan bahan aspal dapat dengan menambahkan bahan lain seperti silika sebagai filler pada aspal [11]. Penggunaan komposit silika sekam padi dengan aspal menghasilkan nilai porositas sebesar 10,2\%, 10\% dan 9,8\% [4]. Abu sekam padi sebagai filler aspal menghasilkan nilai titik lembek sebesar $48{ }^{\circ} \mathrm{C}$ [12]. Aspal penetrasi 60/70 (aspal pen60/70) merupakan jenis aspal yang biasa digunakan di Indonesia dengan daerah cuaca iklim panas dan volume lalu lintas sedang atau tinggi. Aspal silika sekam padi telah dilakukan menggunakan perbandingan massa aspal silika sebesar 20\%:80\%; 15\%:85\%; 10\%: 90\% menghasilkan daya serap air sebesar 7,40\%; 7,22\%, dan 7,12\% [13]. Silika sekam padi dengan aspal juga dilakukan dengan perbandingan $1: 0 ; 1: 0,4 ; 1: 0,5$, dan 1:0,6 menghasilkan daya serap air sebesar $26 \% ; 3 \% ; 1,7 \%$; dan 1,5\% [7]. Penggunaan komposit silika sekam padi dengan aspal juga dilakukan dengan perbandingan massa $1: 0,7 ; 1$ : 0,8; $1: 0,9$ menghasilkan nilai porositas sebesar 10,2 \%, $10 \%$ dan 9,8 \% [4]. Penggunaan serat ijuk juga digunakan dengan penambahan aspal sebesar $0 \%, 0,5 \%, 1 \%, 1,5 \%$, dan $2 \%$ menghasilkan porositas sebesar 13,0 \%, 17,8 \%, 20,4\%, 22,3\%, dan 22,9\% [14]. Penelitian-penelitian yang sudah dilakukan sebelumnya banyak menggunakan paduan aspal pen60/70 dengan filler silika sekam padi tanpa waktu milling. Sehingga, penelitian tentang silika abu sekam padi lebih lanjut perlu dilakukan untuk mengetahui pengaruh silika abu sekam yang dimilling selama 15 jam sebagai filler paduan aspal pen60/70 untuk memperbaiki karakteristik paduan aspal dalam menahan efek suh dan beban aspal.

Pengaruh penambahan silika abu sekam padi sebagai filler pada aspal penetrasi 60/70 dilakukan dalam penelitian ini sebagai alternatif baru yang dapat digunakan sebagai filler paduan aspal. Banyaknya penambahan silika, akan semakin baik untuk penyerapan air pada aspal [7]. Karena, silika memiliki sifat yang sudah berikatan dengan air sehingga baik untuk porositas, kalor jenis dan kapasitas panas dari paduan aspal yang dihasilkan. Variasi silika abu sekam padi yang digunakan adalah tanpa (S0) dan dimilling selama 15 jam (S15). Silika abu sekam padi dipilih sebagai bahan pembuatan silika karena limbah dari pembakaran batu bata yang jumlahnya melimpah dan belum dimanfaatkan secara optimal.

\section{Material dan metodologi}

Alat yang digunakan dalam penelitian adalah neraca digital, mesin press hidrolik, alat uji daya serap air dan porositas, dan alat uji panas (DSC). Sedangkan, bahan yang digunakan adalah abu sekam padi, $\mathrm{NaOH}$, Natrium Silikat, Asam Asetat, aspal dan bensin. Pembuatan dan pengujian komposit peredam bunyi dilakukan di Laboratorium Fisika Inti Material UNSOED dan Laboratorium Bahan Teknik UGM.

\subsection{Tahapan sintesis silika abu sekam padi}

Desain preparasi sintesis silika abu sekam padi ditunjukkan Gambar 1. Gambar 1. merupakan desain proses sintesis silika abu sekam padi dengan metode sol-gel. Proses pembentukan gel melalui reaksi pembentukan ikatan siloksan yaitu $\mathrm{Si}-\mathrm{O}-\mathrm{Si}$ - dari molekul silikat. Abu sekam padi ditambahkan dengan larutan $\mathrm{CH} 3 \mathrm{COOH}$ maka terbentuk hidrogel 
berwarna putih seperti kaca. Gel tersebut kemudian didiamkan selama 18 jam. Kemudian, gel dikeringkan menggunakan oven. Gel yang sudah kering ditimbang menggunakan neraca analitik digital hingga beratnya konstan.

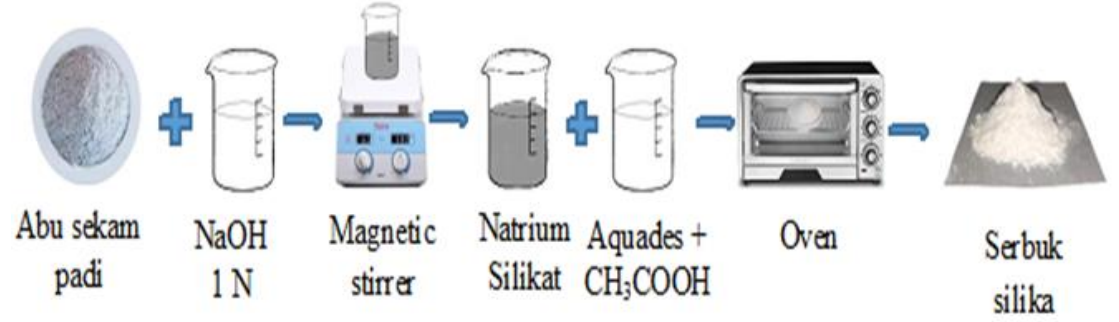

Gambar 1. Desain sintesis silika abu sekam padi

\subsection{Tahapan milling serbuk silika abu sekam padi}

Proses milling digunakan untuk pembentukan nanomaterial menggunakan ball-mill (bola penghancur). Serbuk dimasukkan ke dalam vial dengan ball-mill dan digerakkan secara rotasi maupun vibrasi dengan frekuensi tinggi. Material yang terperangkap di antara dinding vial dengan ball-mill akan saling bertumbukan sehingga menghasilkan deformasi pada material seperti Gambar 2.
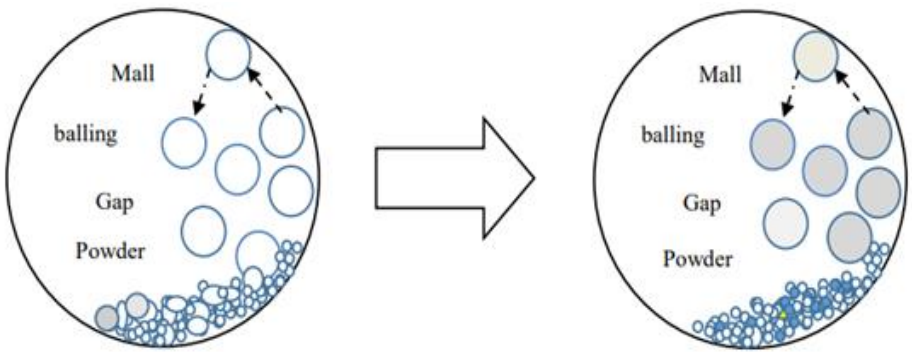

Gambar 2. Mekanisme proses milling [14]

Gambar 2. menunjukkan mekanisme proses milling suatu material hingga terdeformasi. Deformasi material akan menyebabkan fregmentasi struktur material sehingga material akan terpecah dan menjadi susunan atau suatu butiran dengan ukuran lebih kecil. Proses milling menggunakan mesin milling tipe Certiprep 8000M Mixer/mill. Hasil dari proses milling diperoleh silika berbentuk serbuk halus dan digunakan untuk proses pembuatan aspal campuran silika.

\subsection{Tahapan pembuatan pellet paduan silika abu sekam padi dengan aspal pen60/70}

Pembuatan aspal dengan campuran Silika $\left(\mathrm{SiO}_{2}\right)$ tanpa dan dengan milling 15 jam dilakukan dengan cara aspal peneterasi 60/70 sebanyak 20 gram yang dicairkan dengan bensin sebanyak $40 \mathrm{ml}$ dan Silika bubuk sebanyak 40 gram. Silika tanpa dan dengan waktu milling 15 jam ditambahkan ke dalam aspal yang telah dicairkan kemudian kedua bahan diaduk hingga homogen sehingga diperoleh aspal campuran Silika. Pellet paduan aspal Silika. Bahan yang sudah menjadi homogen di oven pada suhu $100^{\circ} \mathrm{C}$ selama 4 jam. Paduan aspal Silika yang sudah kering digerus menggunakan mortar dan disaring untuk mendapatkan serbuk aspal Silika yang homogen.

\subsection{Tahapan pengujian pellet paduan silika abu sekam padi dengan aspal pen60/70}

\subsubsection{Uji Porositas dan Daya Serap Air (Water Absorption)}

Pengujian porositas dan daya serap air menggunakan metode Archimides dilakukan seperti Gambar 4. menunjukkan desaian pengujian porositas dan daya serap air paduan silika abu sekam padi dengan aspal pen60/70. Sampel paduan aspal silika abu sekam padi dengan aspal pen60/70 ditimbang menggunakan neraca digital untuk menentukan massa kering sampel (mk). kemudian, sampel direndam dalam air dalam gelas beker dan divakum selama kurang lebih 2 jam hingga tidak lagi muncul gelembung udara. Untuk pengujian porositas, sampel dikeluarkan dan digantung dengan kawat pada statif 
dalam air dan ditimbang untuk mendapatkan massa gantung (mg). Untuk pengujian daya serap air, sampel dikeluarkan dan air yang berlebih pada permukaannya dihilangkan dengan dilab. Setelah itu, ditimbang untuk mendapatkan massa basah (mb). Kemudian, kawat ditimbang untuk mendapatkan massa kawat (mkw).

\subsubsection{Uji Termal dengan DSC}

Pengujian sifat termal sampel paduan silika abu sekam padi dengan aspal pen60/70 dalam bentuk pellet menggunakan Differential Scanning Calorimetry (DSC) type 60 Shimadzu. Sampel dimasukkan ke dalam pan dengan suhu mulai dari 0 ${ }^{\circ} \mathrm{C}$ hingga $300^{\circ} \mathrm{C}$.

\subsection{Tahapan Analisis Data}

\subsubsection{Pengujian Porositas}

Benda yang dicelupkan seluruhnya atau sebagain ke dalam zat cair, maka zat cair akan memberikan gaya ke atas pada benda yang besarnya sama dengan berat zat cair yang dikeluarkan oleh benda tersebut [16]. Pernyataan ini disebut Hukum Archimedes. Nilai porositas ini berdasarkan ASTM C 20-92 adalah :

$$
\varepsilon=\left[\frac{\boldsymbol{m}_{b}-\boldsymbol{m}_{k}}{\boldsymbol{m}_{\boldsymbol{b}}-\left(\boldsymbol{m}_{g}-\boldsymbol{m}_{k w}\right)}\right] \times 100 \%
$$

Dengan $\varepsilon$ adalah porositas $(\%), \rho_{\text {sampel }}$ adalah densitas sampel, $\rho_{\text {air }}$ adalah densitas air $\left(1000 \mathrm{~kg} / \mathrm{m}^{3}\right), m_{b}$ adalah massa basah, $m_{k}$ adalah massa kering, $m_{g}$ adalah massa benda digantung dalam air dan $m_{k w}$ adalah massa kawat.

\subsubsection{Pengujian Daya Serap Air (Water Absorption)}

Daya serap air merupakan ukuran banyaknya air yang dapat memenuhi volume suatu bahan.. Daya serap air ditentukan dengan persamaan (2) sesuai ASTM C-20-00-2005.

$$
W A=\frac{m_{b}-m_{k}}{m_{k}} \times 100 \%
$$

Dengan WA adalah daya serap air (\%), m_b adalah massa basah sampel, dan $\mathrm{m} \_\mathrm{k}$ adalah massa kering sampel.

\subsubsection{Pengujian Kapasitas Panas dan Kalor Jenis}

Kalor jenis merupakan banyaknya kalor yang diperlukan untuk menaikkan suhu sebesar $1{ }^{\circ} \mathrm{C}$ setiap $1 \mathrm{~kg}$ zat [17]. Kalor ditentukan dengan persamaan (3).

$$
Q=C . \Delta T
$$

Dimana kalor yang disimbolkan Q dengan satuan Joule, m merupakan simbol dari massa dengan satuan $\mathrm{kg}, \mathrm{c}$ simbol dari kalor jenis dengan satuan $\mathrm{J} / \mathrm{kg}^{\circ} \mathrm{C}$, perubahan suhu zat yang disimbolkan $\Delta \mathrm{T}$ dengan satuan ${ }^{\circ} \mathrm{C}$, dan $\mathrm{C}$ simbol dari kapasitas panas dengan satuan $\mathrm{J} /{ }^{\circ} \mathrm{C}$. Hubungan antara kapasitas panas dengan kalor jenis adalah :

$$
\boldsymbol{C}=\boldsymbol{m} \cdot \boldsymbol{c}
$$

Dengan kapasitas panas disimbolkan $\mathrm{C}$ dengan satuan $\mathrm{J} /{ }^{\circ} \mathrm{C}$, m yang merupakan massa dengan satuan $\mathrm{kg}$, dan kalor jenis disimbolkan dengan c yang memiliki satuan $\mathrm{J} / \mathrm{kg}^{\circ} \mathrm{C}$. Flowchart penelitian seperti Gambar 3 . 
Kartika Sari dkk /Jurnal Rekayasa Mesin

p-ISSN: 1411-6863, e-ISSN: 2540-7678

Vol.16|No.3|401-408|Desember|2021
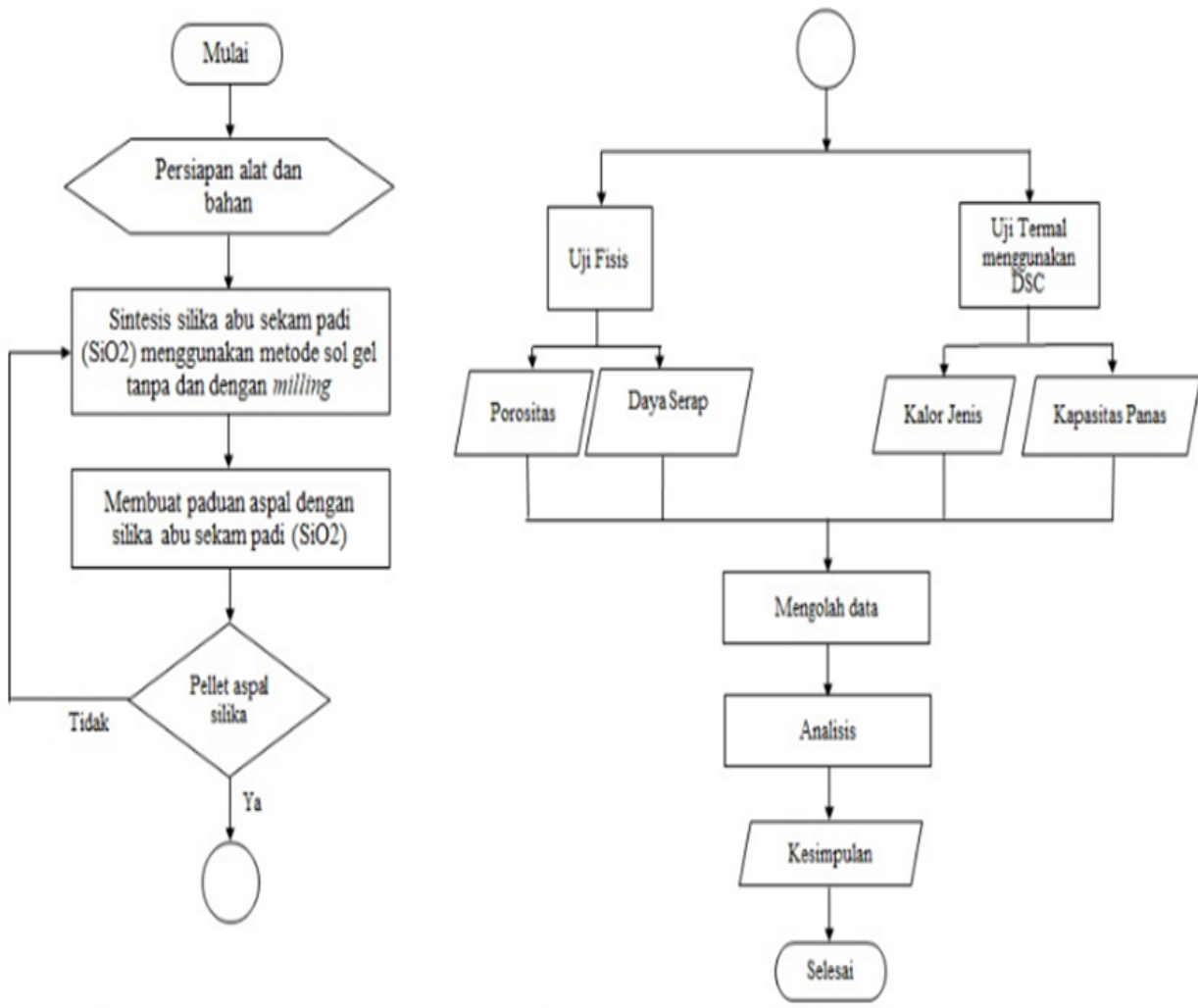

Gambar 3. Flowchart Penelitian

\section{Hasil dan pembahasan}

\subsection{Uji Porositas dan Daya Serap Air (Water Absorption)}

\subsubsection{Uji Porositas}

Hasil pengujian porositas ditunjukkan pada Gambar 4(a). Nilai porositas sampel S0 dan S15 rata-rata sebesar 6,0\% dan $10,7 \%$. Peningkatan porositas tersebut terjadi pada aggregat dengan aspal disebabkan pori di dalam aggregat semakin padat diisi oleh aspal, sehingga butir-butir agregat terdorong oleh aspal [4].

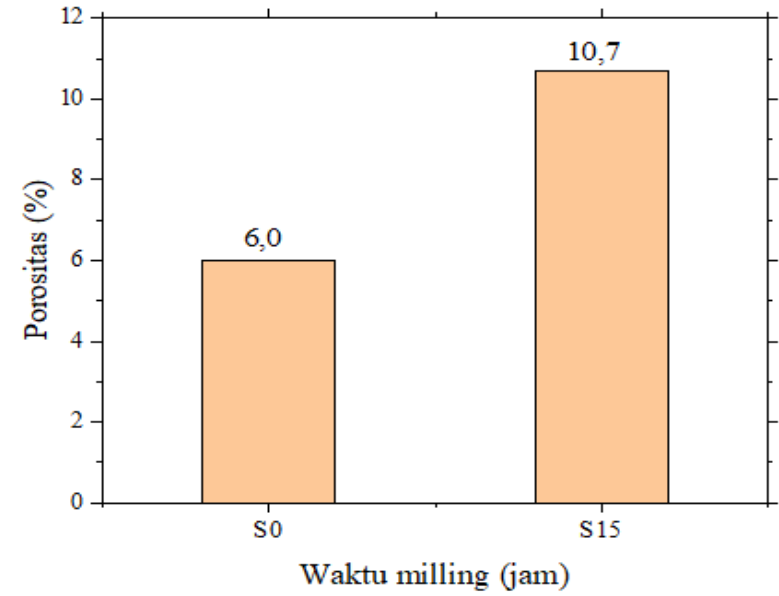

(a)

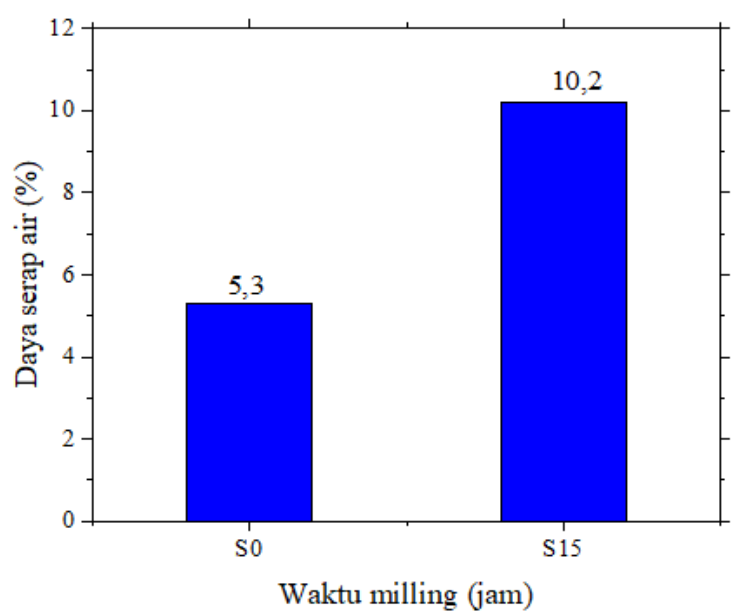

(b)

Gambar 4. Paduan silika abu sekam padi dengan aspal pen60/70 (a) Porositas dan (b) daya serap air 
Jadi, penambahan filler silika abu sekam padi dengan waktu milling 1 menit berpengaruh terhadap kualitas aspal yang dihasilkan. Semakin banyak silika abu sekam padi yang digunakan, maka porositas yang didapat semakin kecil dan massa dari paduan aspal pen60/70 akan bertambah.

\subsubsection{Uji Daya Serap Air}

Hasil pengujian daya serap air ditunjukkan pada Gambar 4(b). Nilai rata-rata daya serap air menunjukkan bahwa sampel S0 sebesar 5,3\% dan sampel S15 sebesar 10,2 \%. Kenaikan daya serap air sampel S15 disebabkan banyaknya pori sehingga air lebih banyak diserap oleh sampel. Semakin banyak pori yang terdapat pada sampel maka semaikn besar juga penyerapan pada sampel [18]. Penambahan silika abu sekam padi dengan waktu milling 15 jam akan meningkatkan nilai daya serap air. Karena butiran-butirannya semakin rapat sehingga celah atau pori-pori semakin besar sehingga membentuk batas butir yang sempurna. Semakin banyak penambahan silika abu sekam padi pada aspal pen60/70 maka nilai daya serap air semakin meningkat.

\subsection{Uji Sifat Termal}

Gambar 5 menunjukkan hasil pengujian sifat termal meliputi kapasitas panas dan kalor jenis silika abu sekam padi S0 dan S15 sebagai filler aspal pen60/70. Untuk S0, nilai kalor jenis, perubahan entalpi, dan kapasitas panas sebesar 7 $\mathrm{J} / \mathrm{kgK} ; 6,913 \times 10^{-3} \mathrm{~mW} / \mathrm{mg}$, dan $151,2 \times 10^{-6} \mathrm{~J} / \mathrm{K}$. Dan, nilai kalor jenis dan perubahan entalpi untuk S15. Nilai kalor jenis, perubahan entalpi dan kapasitas panas sebesar $1 \mathrm{~J} / \mathrm{kgK} ; 10,24 \times 10^{-3} \mathrm{~mW} / \mathrm{mg}$, dan $23,4 \times 10^{-6} \mathrm{~J} / \mathrm{K}$.

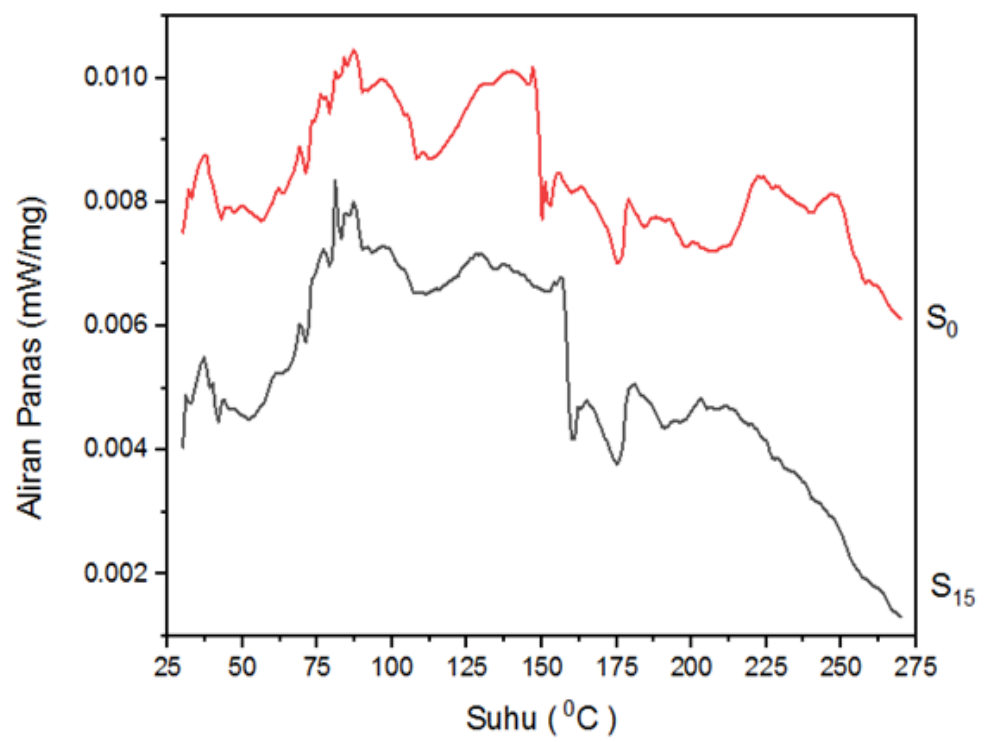

Gambar 5. Hasil DSC untuk sampel S0 dan S15 dengan paduan aspal pen60/70

Gambar 5 menunjukkan perbedaan nilai kalor jenis dan kapasitas panas yang dihasilkan dari sampel S0 dan S15. Nilai kalor jenis S0 lebih tinggi dibandingkan dengan S15, hal ini disebabkan oleh kandungan silika dalam sampel memiliki komposisi yang lebih tinggi dibandingkan dengan S15. Tingginya kandungan silika dalam sampel S0 menyebabkan suhu reaksi pada sampel akan semakin menurun sehingga kalor jenis sampel meningkat dibandingkan dengan sampel S15 sesuai dengan persamaan (3). Sedangkan, nilai kapasitas panas sampel S0 lebih besar dibandingkan S15 disebabkan adanya perbedaan unsur Karbon (C) yang terkadung dalam paduan aspal Silika [19].

\section{Kesimpulan}

Kesimpulan penelitian dengan memanfaatkan silika abu sekam padi sebagai filler pada aspal pen60/70 adalah : 
Kartika Sari dkk /Jurnal Rekayasa Mesin

p-ISSN: 1411-6863, e-ISSN: 2540-7678

Vol.16|No.3|401-408|Desember|2021

hasil uji porositas dan daya serap air diperoleh nilai rata-rata sebesar 6,0 \% dan 5,3\% untuk S0 dan 10,7 \% dan 10,2 \% untuk sampel S15. Kenaikan porositas sampel S15 sebesar 78,3\% dan kenaikan daya serap air sebesar 92,4\%. Sedangkan, hasil uji termal meliputi kalor jenis dan kapasitas panas dari penambahan silika abu sekam padi tanpa dan dengan milling 15 jam terhadap kualitas aspal pen60/70 diperoleh nilai kalor jenis S0 dan S15 sebesar $7 \mathrm{~J} / \mathrm{kgK}$ dan $1 \mathrm{~J} / \mathrm{kgK}$. Sedangkan, nilai kapasitas panas S0 dan S15 sebesar $151,2 \times 10^{-5} \mathrm{~J} / \mathrm{K}$ dan $23,4 \times 10^{-5} \mathrm{~J} / \mathrm{K}$.

\section{Ucapan terima kasih}

Terima kasih kepada Kementrian Ristek/BRIN melalui Universitas Jenderal Soedirman melalui pendanaan BLU Skim Riset Peningkatan Kompetensi Tahun 2021.

\section{Daftar Pustaka}

[1] Kristiano, Rikardus., Suryana., Upi Supriatna. Perkembangan Sarana dan Prasarana Transportasi dalam Hubungan dengan Tingkat Perekonomian Masyarakat di Desa Kolang Kecamatan Kuwus Barat, Kabupaten Manggarai Barat, Provinsi Nusa Tenggara Timur. Jurnal Geofrafi Gea. 2019; 19 (2): p.132.

[2] Fahmi, H dan Falah, A.L. Analisa Daya Serap Silika Gel Berbahan Dasar Abu Sekam Padi. Padang: Fakultas Teknologi Industri Teknologi Padang; 2016.

[3] Diana, L.O, Simon S, dan Rudy T.M.S. Pengaruh Penambahan Silika (SiO2) Sekam Padi Terhadap Karakteristik Mikrostruktur dan Struktur Aspal dengan Perbandingan Massa 1:0; 1:1,5; 1:1,6 dan 1:1,7. Jurnal Teori dan Aplikasi Fisika. 2018; 7 (1): p.36.

[4] Suka E.G. Karakteristik Struktur Mikro dan Gugus Fungsi Komposit Silika Sekam Padi dan Aspal. Jurnal Teori dan Aplikasi Fisika. 2019; 8 (1): p.98.

[5] Huljana M., Rodiah S. Sintesis Silika dari Abu Sekam Padi dengan Metode Sol-Gel. Palembang : Universitas Negeri Raden Fatah Palembang; 2019.

[6] Kalapathy, U. A. Proctor, Shultz, J. An Improved method for production of silica from rice hull ash. Bioresource Technology. USA: University of Arkansas; 2002

[7] Ardaniswari. Karakteristik Termal dan Fungsionalitas Komposit Silika Sekam Padi dengan Aspal. Jurnal Teori dan Aplikasi Fisika. 2020; 8 (1).

[8] Rahman, Arif. Pembuatan Nanosilika Gel Dari Silika Abu Sekam Padi. Skripsi. Makassar. Universitas Islam Negeri Alauddin; 2017.

[9] Dalimunthe, Muhammad Rasyad Tahir dan Melloukey Ardan. Analisa Karakterisistik Campuran Aspal Beton dengan Filler yang Berbeda Terhadap Nilai Marshall. Journal of Civil Engineering, Building and Transportation. 2019; 3 (1): p.19-26.

[10] Qin. Characterization of Asphalt Mastics Reinforced with Basalt Fibers. Construction and Building Materials; 2018. P. $159(508-516)$.

[11] Susanti, N. Pengaruh Perlakuan Termal Terhadap Karakteristik Aspal Komposit Berbasis Silika Sekam Padi. Jurnal Teori dan Aplikasi Fisika. 2020; 8 (1): p.120.

[12] Hidayanti, E.T, Fauziah M. Pengaruh Abu Sekam Padi Sebagai Filler Pengganti Terhadap Karakteristik Campuran Stone Matrix Asphalt (SMA). Yogyakarta : Universitas Islam Indonesia. 2018 
[13] Widwiyantoro. Sintesis dan Karakteristik Struktur, Sifat Fisis, dan Sifat Mekanik Komposit Aspal Silika Dengan Variasi Komposisi Aspal Silika (20\%:80\%wt; 15\%:85\%wt; 10\%:90\%wt). Journal of Energy, Material dan Instrumentation Technology. 2020; 1 (2).

[14] Karyawan. Pengaruh Penambahan Serat Ijuk Terhadap Porositas dan Permeabilitas Campuran Aspal Porus. Jurnal Sipilsains. 2020; 10 (2): p.147.

[15] Kartika Sari. Microstructures and Functional Group Properties of Nano-Sized Chitosan Prepared by Ball Milling. Jurnal Materials Science Forum. 2019; 948: p.192-197.

[16] Giancoli D.C. 2014. FISIKA: Prinsip dan Aplikasi. Jakarta : Erlangga.

[17] Munsil, D.P. 2018. Dasar Manajemen Kontruksi Proyek Jalan (TAHAPAN PRE-START). Sleman: Deepublish.

[18] Akbar. 2021. Modifikasi beton polimer dengan menggunakan senyawa lateks karet alam terlalu matang (overcured) dan pengisi white rice husk ash (WRHA). Skripsi. Medan. Universitas sumatra utara.

[19] Lody, Andreas. 2019. Analisis Perbandingan Campuran Komposisi Karbon, Semen, dan Air Terhadp Laju Konduktivitas Panas, Kapasitas Kalor, dan Efesiensi Kapasitas Kalor. Skripsi. Malang. Universitas Katolik Widya Karya. 